\title{
Secagem de grãos residuais de urucum por exposição direta ao sol combinada com secagem em secador acumulador de calor
}

\section{Drying grain residual annatto by sun combined with drying in dryer with heat accumulator}

\author{
Dyego da Costa Santos ${ }^{1 *}$; Alexandre José de Melo Queiroz ${ }^{2}$; \\ Rossana Maria Feitosa de Figueirêdo ${ }^{2}$; Emanuel Neto Alves de Oliveira ${ }^{3}$
}

\section{Resumo}

O processo de extração do pigmento bixina resulta em uma grande quantidade de grãos residuais de urucum. A maior parte desse material é descartada, mas é possível aproveitá-lo incorporando-o em rações para animais e na alimentação humana. Neste trabalho, objetivou-se secar grãos residuais de urucum utilizando energia solar. Os grãos foram divididos em dois lotes, um com óleo, reproduzindo as condições dos grãos após a extração oleosa de bixina e outro lote sem óleo. As secagens foram realizadas durante o dia em base de concreto recoberta com lona de polietileno preta, com as amostras em bandejas e expostas ao sol; durante a noite metade das amostras foi posta a secar em secador acumulador de calor e a outra metade ficou em bancada de laboratório para controle. Os grãos apresentaram teores de umidade inicial e final de aproximadamente $18 \%$ b.u. e $5 \%$ b.u., respectivamente. A utilização do secador acumulador de calor no período noturno possibilitou a obtenção de amostras com razão de umidade abaixo de 0,1 na noite do primeiro dia de secagem, enquanto as amostras controle absorveram água no período noturno. Todos os modelos estudados apresentaram bom ajuste aos dados experimentais, com valores de coeficientes de determinação superiores a 0,95 e valores de desvios quadráticos médios inferiores a 0,1 . Os coeficientes de difusividade foram da ordem de $10^{-9} \mathrm{~m}^{2} \mathrm{~s}^{-1}$, para todos os tratamentos estudados, com as amostras de grãos sem óleo apresentando o maior valor.

Palavras-chave: Bixa orellana L., secagem solar, resíduos agrícolas

\begin{abstract}
The process of extraction of the pigment bixin results in a large amount of residual grain annatto. Most of this material is discarded, but you can enjoy it by incorporating it into animal feed and human food. This study aimed to dry grain residual annatto using solar energy. The beans were divided into two batches, one with oil, reproducing conditions of the grains after extraction of bixin oil, and other oilfree. The drying was performed during the day in the concrete base covered with black polythene bag with samples in trays and exposed to the sun; overnight half of the samples was placed in a dryer to dry heat accumulator and the other half was in bench laboratory for control. The grains showed levels of initial and final moisture of about $18 \% \mathrm{wb}$ and $5 \% \mathrm{wb}$, respectively. Use the dryer heat accumulator at night allowed the collection of samples with the moisture ratio below 0.1 in the evening of the first day of drying, while the control samples absorbed water during the night. All models studied showed good fit to experimental data, with values of determination coefficients above 0.95 and average values of the squared deviations of less than 0.1 . The diffusivity coefficients were of the order of $10^{-9} \mathrm{~m}^{2} \mathrm{~s}^{-1}$ for all treatments, with the grain samples without oil showing the greatest value.
\end{abstract}

Key words: Bixa orellana L., solar drying, agricultural residues

\footnotetext{
${ }^{1}$ Discente do curso de Doutorado em Engenharia Agrícola da Universidade Federal de Campina Grande, UFCG, Campina Grande, PB. E-mail: dyego.csantos@gmail.com

${ }^{2}$ Profs.da UFCG, Campina Grande, PB. E-mail: alex@deag.ufcg.edu.br; rossana@deag.ufcg.edu.br

${ }^{3}$ Prof. do Instituto Federal de Educação, Ciência e Tecnologia do Rio Grande do Norte, IFRN, Campus Pau dos Ferros, RN. E-mail: emanuelnetoliveira@ig.com.br

* Autor para correspondência
} 


\section{Introdução}

O urucuzeiro (Bixa orellana L.) é uma planta originária da América do Sul, especificamente da região amazônica. O pericarpo das sementes de urucum possui uma cobertura rica em pigmentos dos quais se produz um corante natural muito usado em vários setores industriais, em particular no de alimentos (CORLETT; BARROS; VILLELA, 2007; PARIZE; SOUZA; BRIGHENTE, 2008; SANTOS et al., 2013). De acordo com Cardarelli, Benassi e Mercadante (2008), o corante extraído do urucum é utilizado para coloração de manteiga, queijo, produtos de panificação, óleos, gelados comestíveis, salsichas, cereais e produtos extrusados, sendo relativamente barato quando comparado com outros pigmentos naturais.

Os principais pigmentos presentes no urucum são os carotenóides bixina e norbixina (CARDEÑOSA; LUNAR; RUBIO, 2011). Dentre estes, a bixina representa cerca de $80 \%$ do total (PARIZE; SOUZA; BRIGHENTE, 2008). O processo de extração da bixina produz de 97 a 98\% de resíduo, constituído pelos grãos e óleo de soja aderido (SILVAet al., 2005). Rêgo et al. (2010) relatam que aproximadamente 2.500 t de resíduos do urucum são obtidos no Brasil a cada ano, e os autores estimam em mais de $95 \%$ o percentual de resíduo não aproveitado. Estudos têm sido realizados sobre a incorporação desses grãos residuais na alimentação animal, com resultados positivos (SILVA et al., 2005; HARDER et al., 2007; SILVA et al., 2009; CARVALHO et al., 2009; OFOSU et al., 2010; RÊGO et al., 2010), seguindo tendência mundial de pleno aproveitamento de resíduos e subprodutos agrícolas (JITTANIT, 2011). Os resíduos de grãos de urucum, além ser matéria-prima com considerável valor nutricional apresentando valores consideráveis de proteínas, fibras e minerais, também podem ser usados para aumentar a rentabilidade do produto principal (TONANI et al., 2000; QUEIROZ et al., 2011). Contudo, não foram encontrados estudos sobre o uso na alimentação humana.
Trabalhos sobre secagem de resíduos agrícolas incluem resíduos da extração do azeite de oliva (MONTERO et al., 2010; VEGA-GALVEZ et al., 2010), sementes de abóbora (JITTANIT, 2011), resíduos de laranja (GARAU et al., 2006, 2007), bagaço de cenoura (KUMAR; SARKAR; SHARMA, 2012), resíduos de cevada maltada provenientes de indústrias de cerveja (TANG; CENKOWSKI; IZYDORCZYK, 2005), resíduos de gergelim (AL-MAHASNEH et al., 2007), sementes de uva (ROBERTS; KIDD; PADILLA-ZAKOUR, 2008), bagaço de cana de açúcar (VIJAYARAJ; SARAVANAN; RENGANARAYANAN, 2007), bagaço de coco (JENA; DAS, 2007), bagaço de maçã (WANG et al., 2007), resíduos de romã (DOYMAZ, 2012), resíduo da indústria de processamento de goiaba (KONG et al., 2010), entre outros. Apesar da grande diversidade de estudos utilizando resíduos agrícolas, não foram encontradas pesquisas abordando a secagem de grãos residuais de urucum provenientes da indústria de extração da bixina.

Para estocagem e comercialização de produtos agrícolas é necessário reduzir a quantidade de água do material e consequentemente sua atividade biológica. A secagem surge, então, como o processo mais utilizado para prolongar sua vida útil, por garantir estabilidade durante a armazenagem (SANTOS et al., 2013). Dentre os vários métodos de secagem utilizados comercialmente, Doymaz e Ismail (2011) descrevem a secagem por exposição direta ao sol, caso em que o produto é exposto à radiação solar direta. Uma parte do calor gerado migra para o interior do produto, provocando o aumento da temperatura e a formação de vapor de água, e a quantidade restante é utilizada na evaporação da umidade a partir da superfície. A umidade e o vapor de água se difundem do interior do grão para a superfície a fim de substituir a perda de umidade por evaporação (PRASAD; VIJAY, 2005).

Os processos de secagem que utilizam energia solar podem ser uma tecnologia muito atraente para o tratamento dos resíduos agrícolas, uma vez que 
além de eliminarem os gastos com energia elétrica, ajudam a reduzir os impactos ambientais causados pelo descarte desses resíduos. Países tropicais como o Brasil dispõem de um grande potencial para uso de energia solar, com períodos do ano com pouca nebulosidade, baixa umidade relativa do ar e elevada incidência de radiação solar.

A secagem por exposição ao sol é um dos mais antigos métodos de uso de energia solar para a conservação de alimentos (BELESSIOTIS; DELYANNIS, 2011). Desde os tempos préhistóricos, a humanidade usou a radiação solar como única fonte de energia térmica disponível para secar e preservar todos os gêneros alimentícios necessários para o inverno. No entanto, Doymaz e Ismail (2011) citam a lentidão do processo como uma das desvantagens da secagem por exposição direta ao sol. A lentidão das secagens pode ser atribuída às condições meteorológicas, como nebulosidade e chuva, e à interrupção do processo durante o período noturno. De acordo com Queiroz et al. (2011), estudos para superar esse inconveniente devem considerar a acumulação de energia solar durante o dia, a fim de manter a secagem durante a noite, mesmo que a uma menor taxa. Nesse sentido, a utilização de água com a finalidade acumular energia solar tem a vantagem de poder ser realizada em um volume de líquido relativamente pequeno e com a utilização de coletores solares simples.

Poucos são os trabalhos disponíveis na literatura que consideram armazenar energia solar para utilizarem em secagens no período noturno: Fagunwa, Koya e Faborode (2009) desenvolveram um secador solar com armazenamento de energia térmica em fragmentos de rochas (cascalho) durante o dia para secagem de sementes de cacau no período noturno; os referidos autores utilizaram sementes com teor de água inicial de $53,4 \%$ b.u. e conseguiram reduzir esse teor até $3,6 \%$ b.u. em 72 $\mathrm{h}$ intermitentes de secagem. Queiroz et al. (2011) utilizaram um secador acumulador de energia solar em água no período diurno para secagem de amêndoas de jaca no período noturno e constataram que o uso do secador acumulador foi tecnicamente viável para secagens noturnas, com obtenção de amostras com baixo teor de umidade.

Objetivou-se com este estudo secar grãos residuais de urucum por exposição direta ao sol combinada com secagem em secador acumulador de calor para uso noturno, estudar a cinética de secagem por meio de modelos matemáticos $\mathrm{e}$ determinar o coeficiente de difusividade.

\section{Material e Métodos}

Os grãos residuais de urucum, provenientes da indústria alimentícia Maratá com sede no Estado de Sergipe, foram transportados ao laboratório em embalagens plásticas e submetidos a processo de seleção para remoção de sujidades como fragmentos de folhas e talos. Esses grãos apresentavam-se impregnados de óleo de soja oriundo do processo de obtenção da bixina. A manipulação dos grãos foi realizada de dois modos: no primeiro, os grãos foram conservados com a camada de óleo proveniente do processo de extração dos pigmentos (Tratamento 1), e no segundo a camada de óleo foi removida através de lavagens dos grãos em água e em detergente neutro (Tratamento 2). Após a lavagem, os grãos foram distribuídos em camada fina em bancada de laboratório até evaporação da água superficial.

Os experimentos foram realizados com 4 repetições, em camada fina, e cada repetição foi constituída por aproximadamente $15 \mathrm{~g}$ de amostra, fracionada em cestas montadas com tela de arame $(10 \times 10 \times 3 \mathrm{~cm})$. Antes do início da secagem, foi determinado o teor de umidade inicial das amostras dos tratamentos 1 e 2 , em estufa a $105 \pm 3{ }^{\circ} \mathrm{C}$, de acordo com metodologia da AOAC (2010). As amostras apresentavam no início das secagens teor de umidade de aproximadamente $18 \%$ b.u. $(21,95 \%$ b.s.).

As secagens eram iniciadas aproximadamente às $8 \mathrm{~h}$, realizadas sobre base de concreto recoberta com lona de polietileno preta, com as amostras 
colocadas em bandejas e expostas ao sol. A partir das $17 \mathrm{~h}$, metade das amostras era colocada para secagem noturna no secador acumulador de calor (descrito adiante), e a outra metade era abrigada em laboratório (amostra controle). A secagem noturna era encerrada às $8 \mathrm{~h}$ da manhã do dia seguinte, quando as amostras provenientes do secador acumulador de calor e as amostras controle voltavam para exposição direta ao sol. Esse ciclo continuava até as amostras atingirem o teor de umidade desejado. As perdas de água foram acompanhadas por pesagens em tempos regulares de 15, 30, 60, 120, 180 e $240 \mathrm{~min}$. As secagens eram encerradas quando as amostras atingiam uma umidade aproximada de $5 \%$ b.u. $(5,26 \%$ b.s. $)$, determinando-se então o teor exato de umidade final em estufa a $105{ }^{\circ} \mathrm{C}$ (AOAC, 2010). Durante o processo de secagem no secador acumulador de calor, foram monitoradas as temperaturas e umidades relativas no interior da câmara de secagem e ambiente.

O secador acumulador de calor (Figura 1) é um equipamento que acumula calor proveniente da radiação solar e permite utilizá-lo em secagens durante a noite. Funciona com base em coletores solares aquecedores, reservatório de água e câmara de secagem, formando dois circuitos ligados por tubos providos de registros para controle de circulação da água. Durante o dia, a água tem circulação restrita ao primeiro circuito (coletores solares/reservatório térmico). Na operação diurna, a circulação da água entre os coletores solares e o reservatório é levada a efeito com base no princípio do sifão térmico combinado com bomba de água operada com energia fotovoltaica; a água aquecida nos coletores solares percorre uma tubulação ascendente desde a saída superior do coletor localizado na posição mais alta em relação aos demais, até a entrada do reservatório, localizada na posição mais alta de todo o circuito. Ao ascender pelo efeito convectivo produzido pelo aquecimento, um sifão térmico succiona a água fria da parte inferior do reservatório em direção à entrada do coletor localizado na posição mais baixa em relação aos demais, promovendo assim a circulação; a bomba de água movida a energia fotovoltaica acelera o movimento da água, possibilitando aquecimento mais rápido nos coletores solares em eventos de sol aberto, com menores tempos de residência e consequente melhoria no aproveitamento. Para as secagens durante a noite, a circulação neste circuito é interrompida, sendo então liberada a circulação no segundo circuito (reservatório de água/câmara de secagem). A água aquecida é utilizada na secagem noturna pela passagem por um trocador de calor elaborado em tubo de cobre espiralado instalado na câmara de secagem. Durante a noite, a circulação da água se dá exclusivamente por sifão térmico, passando pelo trocador de calor, localizado abaixo da bandeja das amostras. Ao passar pelo trocador de calor, a água se resfria e desce para a parte inferior do circuito (parte inferior do reservatório), succionando, em um sifão térmico inverso ao do primeiro circuito, a água quente da parte superior do reservatório. 
Figura 1. Representação esquemática do secador acumulador de calor: $1=$ coletor solar, $2=$ reservatório térmico, 3=câmara de secagem, 4=reservatório para reposição da água perdida por evaporação, 5=registro, 6=bomba de água e $7=$ painel fotovoltaico.

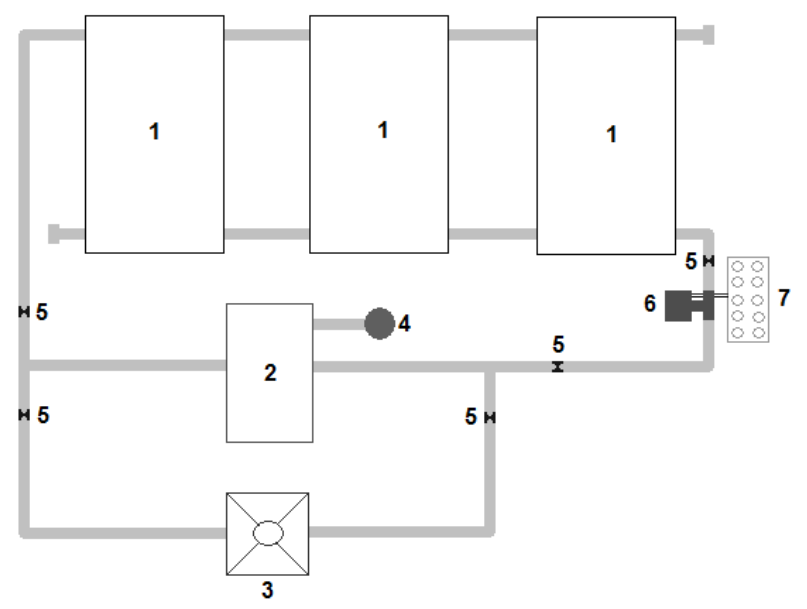

Fonte: Adaptado de Diógenes (2010).

As razões de umidade em função do tempo de secagem foram calculadas a partir dos dados de perda de massa e dos teores de umidade determinadas no final das mesmas, utilizando-se a Eq. 1.

$$
R X=\frac{X_{t}-X_{f}}{X_{i}-X_{f}}
$$

em que:

$\mathrm{RX}=$ razão de umidade do produto (adimensional);
$\mathrm{X}_{\mathrm{t}}=$ teor de umidade do produto em um determinado ponto de secagem, b.s.;

$\mathrm{X}_{\mathrm{i}}=$ teor de umidade inicial do produto, b.s.;

$\mathrm{X}_{\mathrm{f}}=$ teor de umidade final do produto, b.s.

Os modelos matemáticos de Aproximação da Difusão, Dois Termos, Midilli, Page e Thompson (Tabela 1) foram ajustados aos dados experimentais utilizando-se o software Statistica 6.0 por regressão não linear pelo método Quasi-Newton.

Tabela 1. Modelos matemáticos utilizados para ajustar os dados de secagem dos grãos com e sem óleo.

\begin{tabular}{cccc}
\hline Designação do modelo & Referência & Modelo & \\
\hline Aproximação da Difusão & (AKPINAR, 2008) & $\mathrm{RX}=\mathrm{a} \cdot \exp (-\mathrm{k} . \mathrm{t})+(1-\mathrm{a}) \cdot \exp (-\mathrm{k} . \mathrm{b} . \mathrm{t})$ & $(2)$ \\
Dois Termos & (JITTANIT, 2011) & $\mathrm{RX}=\mathrm{a} \cdot \exp (-\mathrm{k} . \mathrm{t})+\mathrm{b} . \exp (-\mathrm{q} . \mathrm{t})$ & $(3)$ \\
Midilli & (MIDILLI; KUCUK; YAPAR, 2002) & $\mathrm{RX}=\mathrm{a} \cdot \exp \left(-\mathrm{k} . \mathrm{t}^{\mathrm{n}}\right)+\mathrm{b} . \mathrm{t}$ & $(4)$ \\
Page & (ROBERTS; KIDD; PADILLA- & $\mathrm{RX}=\exp \left(-\mathrm{k} . \mathrm{t}^{\mathrm{n}}\right)$ & $(5)$ \\
Thompson & ZAKOUR, 2008) & $\mathrm{RX}=\exp \left(\left(-\mathrm{a}-\left(\mathrm{a}^{2}+4 . \mathrm{b} . \mathrm{t}\right)^{0,5}\right) / 2 . \mathrm{b}\right)$ & $(6)$ \\
\hline
\end{tabular}

$\mathrm{RX}$ - razão de umidade, adimensional; $\mathrm{a}, \mathrm{b}, \mathrm{k}, \mathrm{n}, \mathrm{q}$ - parâmetros do modelo, adimensional; $\mathrm{t}$ - tempo de secagem, min. Fonte: Elaboração dos autores; 
As taxas de secagem foram calculadas a partir dos dados de teor de umidade das amostras e dos tempos de secagem, de acordo com a Eq. 7.

$$
\mathrm{TX}=\frac{\mathrm{X}_{\mathrm{t}+\mathrm{dt}}-\mathrm{X}_{\mathrm{t}}}{\mathrm{dt}}
$$

em que:

$\mathrm{TX}=$ taxa de secagem, $\min ^{-1}$;

$\mathrm{X}_{\mathrm{t}+\mathrm{dt}}=$ teor de umidade em $\mathrm{t}+\mathrm{dt}$, (kg de água/kg de matéria seca);

$\mathrm{X}_{\mathrm{t}}=$ teor de umidade no tempo $\mathrm{t},(\mathrm{kg}$ de água/kg de matéria seca);

$\mathrm{t}=$ tempo de secagem, min.

$\mathrm{Na}$ avaliação dos ajustes dos modelos, foram utilizados o coeficiente de determinação $\left(R^{2}\right)$ e o desvio quadrático médio (DQM), (Eq. 8).

$$
\mathrm{DQM}=\left[\frac{1}{\mathrm{n}} \sum_{\mathrm{i}=1}^{\mathrm{n}}\left(\mathrm{RX}_{\text {pred,i }}-\mathrm{RX}_{\text {exp }, \mathrm{i}}\right)^{2}\right]^{\frac{1}{2}}
$$

em que:

$\mathrm{DQM}=$ desvio quadrático médio;

$\mathrm{RX}_{\text {pred }}=$ razão de umidade predita pelo modelo;

$\mathrm{RX}_{\exp }=$ razão de umidade experimental;

$\mathrm{n}=$ número de observações.

Para a determinação do coeficiente de difusividade, ajustou-se os dados da secagem dos grãos ao modelo da difusão líquida para a forma esférica (CRANK, 1975), com aproximação por três termos (Eq. 9), considerando a distribuição da umidade inicial uniforme, a ausência de qualquer resistência térmica e a manutenção do raio da esfera equivalente inicial dos grãos ao longo da secagem. Utilizou-se o software Statistica 6.0, através de regressão não linear, para ajuste do modelo difusional aos dados de secagem.

$$
R X=\frac{X_{t}-X_{f}}{X_{i}-X_{f}}=\frac{6}{\pi^{2}} \sum_{n=1}^{\infty} \frac{1}{n^{2}} \exp \left[-\frac{n^{2} \pi^{2} D_{e f} t}{R_{e q}^{2}}\right] \text { (9) }
$$

em que:

$\mathrm{RX}=$ razão de umidade, adimensional;

$\mathrm{D}_{\text {ef }}=$ Coeficiente de difusividade, $\mathrm{m}^{2} \mathrm{~s}^{-1}$;

$\mathrm{n}=$ número de termos;

$\mathrm{R}_{\mathrm{eq}}=$ raio da esfera equivalente, $\mathrm{m}$;

$\mathrm{t}=$ tempo, $\mathrm{s}$.

Para o cálculo do raio da esfera equivalente determinou-se o volume de 100 grãos (50 grãos com óleo e 50 grãos sem óleo) pelo método de deslocamento de massa (MOHSENIN, 1986), sendo o raio equivalente determinado por meio do volume da esfera (Eq. 9).

$$
\mathrm{V}_{\mathrm{g}}=\frac{4}{3} \pi \mathrm{r}^{3}
$$

em que:

$\mathrm{V}_{\mathrm{g}}$ - volume do grão, $\mathrm{m}^{3}$;

$r-$ raio da esfera equivalente, $m$.

\section{Resultados e Discussão}

Têm-se nas Figuras 2 e 3 os valores médios da temperatura e umidade relativa registrados durante as secagens dos grãos residuais de urucum no ambiente externo e no interior do secador acumulador de calor. As temperaturas e umidades relativas médias no interior do secador acumulador de calor foram de $44,8{ }^{\circ} \mathrm{C}$ e $63,9 \%$ (tratamento 1 ) e $40,7{ }^{\circ} \mathrm{C}$ e $60,2 \%$ (tratamento 2), enquanto que, para o mesmo período, os valores médios desses parâmetros no ambiente do laboratório onde permaneceram as amostras controle foram de $22,7{ }^{\circ} \mathrm{C}$ e $81,3 \%$ (tratamento 1) e 24,1 ${ }^{\circ} \mathrm{C}$ e $75,6 \%$ (tratamento 2). Apesar da temperatura registrada no interior do secador ir diminuindo com o decorrer da secagem, a temperatura média permaneceu acima de $40{ }^{\circ} \mathrm{C}$, superando a do ambiente externo em até $97 \%$. 
Figura 2. Variação da temperatura (A) e umidade relativa (B) no secador acumulador de calor e no ambiente externo durante as secagens das amostras de grãos residuais de urucum com óleo (tratamento 1).
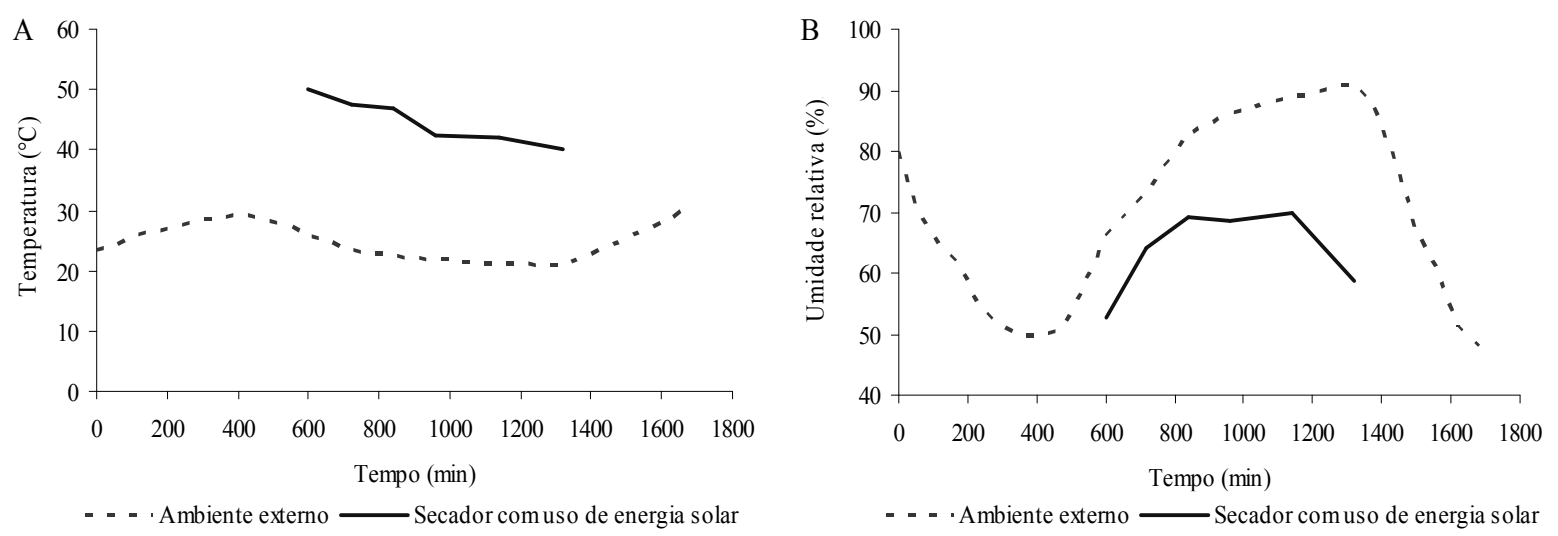

Fonte: Elaboração dos autores.

Figura 3. Variação da temperatura (A) e umidade relativa (B) no secador acumulador de calor e no ambiente externo durante as secagens das amostras de grãos residuais de urucum sem óleo (tratamento 2).
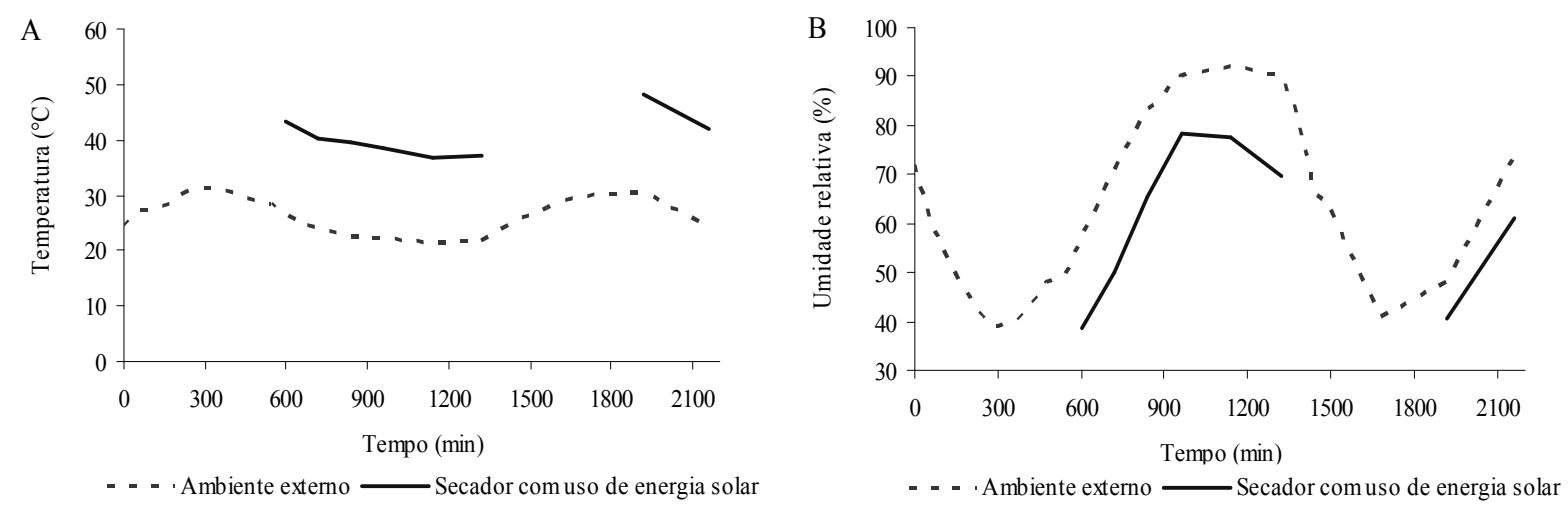

Fonte: Elaboração dos autores.

$\mathrm{Na}$ Figura 4, apresentam-se as curvas de secagem das amostras dos tratamentos 1 e 2, desidratadas por exposição direta ao sol no período diurno, combinado com secagens em secador acumulador de calor no período noturno. No período diurno, referente ao primeiro dia de secagem, ambos os tratamentos perderam umidade em velocidade semelhante. 
Figura 4. Secagem das amostras de grãos residuais de urucum com óleo (A) e sem óleo (B) por exposição direta ao sol combinada com secagem em secador acumulador de calor. Obs: $\mathrm{P}$ - Período de secagem, em que $\mathrm{P}_{1}$ e $\mathrm{P}_{3}$ correspondem ao período diurno e $\mathrm{P}_{2}$ e $\mathrm{P}_{4}$ correspondem ao período noturno.

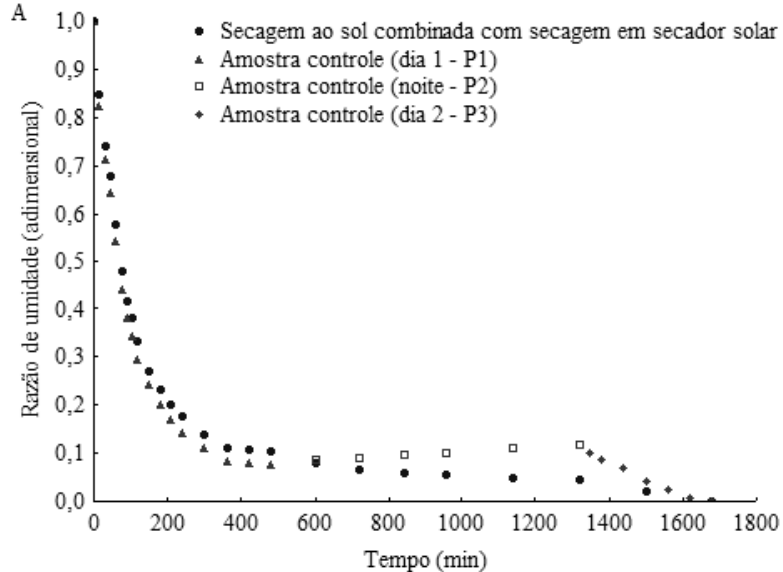

Fonte: Elaboração dos autores.

No período noturno, as amostras em secador acumulador de calor continuaram a perder umidade, enquanto as amostras controle absorveram umidade. No período diurno referente ao segundo dia de secagem por exposição ao sol, as amostras dos tratamentos 1 e 2 continuaram a perder umidade com o tempo, no entanto a uma velocidade inferior às amostras controle, que haviam absorvido umidade no período noturno. A secagem do tratamento 1 foi interrompida aos $1680 \mathrm{~min}(28,00 \mathrm{~h})$ do inicio da desidratação, quando as amostras atingiram teor de umidade de aproximadamente $5 \%$ b.u. A secagem do tratamento 2 teve prosseguimento, agora em secador acumulador de calor (segundo período noturno), onde as amostras continuaram a perder umidade, enquanto que a amostra controle absorveu umidade. $\mathrm{O}$ teor de umidade de $5 \%$ foi atingido no secador acumulador de calor aos $2160 \min (36,00$ h) do inicio da secagem. Em iguais períodos, as amostras controle dos tratamentos 1 e 2 apresentaram teores de umidade superiores a 5,5\%, corroborando com os resultados de Queiroz et al. (2011) que ao desidratarem amêndoas de jaca por exposição ao sol combinada com secagem em secador acumulador de energia solar reportaram menores teores de umidade nas amostras postas a secar no secador acumulador.

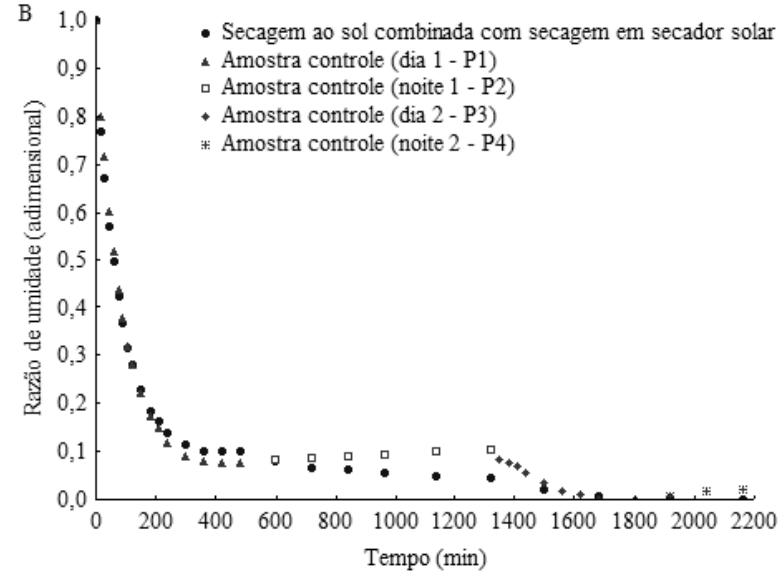

Tendo em vista a temperatura amena no interior do secador acumulador de calor, de cerca de $42{ }^{\circ} \mathrm{C}$ em média para os tratamentos 1 e 2 , a diferença nos tempos de secagem em relação ao controle situouse no nível esperado.

Na Figura 5 são apresentadas as taxas de secagem dos grãos expostos ao sol combinada com secagem em secador acumulador de calor, assim como as taxas de secagem das amostras controle. No início da secagem, as amostras do tratamento 2 apresentaram a maior taxa de secagem, de $0,28 \mathrm{~min}^{-1}$, enquanto as amostras do tratamento 1 revelaram taxa de secagem $0,1 \mathrm{~min}^{-1}$ inferior quando comparado ao tratamento 2, correspondendo a $0,18 \mathrm{~min}^{-1}$. A menor taxa de secagem das amostras do tratamento 1 deve-se provavelmente à capacidade do óleo em formar uma barreira física na superfície dos grãos, dificultando a perda de umidade. Após alguns minutos as taxas dos dois tratamentos se aproximam, indicando que a influência do filme superficial de óleo se torna desprezível diante do movimento de fuga das moléculas de água promovido pela energia de aquecimento. Estes resultados sugerem que a remoção do óleo dos grãos residuais de urucum não se justifica levando-se em conta apenas o critério da taxa de secagem. Em todas as amostras se observa 
perda mais acentuada de umidade nos primeiros 200 minutos, corroborando resultados que associam maior demanda energética a etapas finais de secagem (SACILIK, 2007; NUTHONG et al., 2011; JITTANIT, 2011; SANTOS et al., 2012, 2013).
$\mathrm{Na}$ Tabela 2 são apresentados os teores de umidade inicial e final das amostras dos tratamentos 1 e 2 referentes à secagem dos grãos residuais de urucum por exposição direta ao sol combinada com secagem em secador acumulador de calor.

Figura 5. Taxa de secagem das amostras de grãos residuais de urucum desidratados por exposição direta ao sol combinada com secagem em secador acumulador de calor (A) e amostras controle (B).
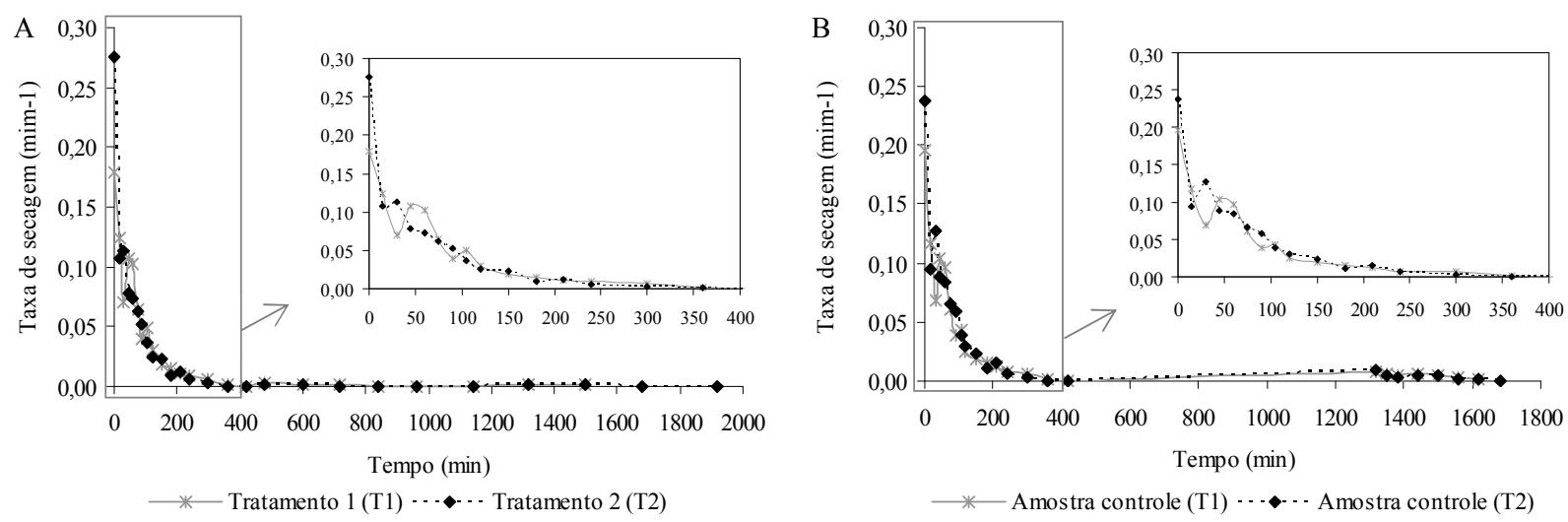

Fonte: Elaboração dos autores.

Tabela 2. Teores de umidade inicial e final (\% b.s.) das amostras de grãos residuais de urucum desidratadas por exposição direta ao sol combinada com secagem em secador acumulador de calor.

\begin{tabular}{|c|c|c|c|c|c|c|c|}
\hline \multirow{2}{*}{$\begin{array}{l}\text { Período de } \\
\text { secagem }\end{array}$} & \multirow{2}{*}{ Tratamento } & \multicolumn{3}{|c|}{ Secagem por exposição direta ao sol } & \multicolumn{3}{|c|}{ Amostra controle } \\
\hline & & Inicial & Final & PU (\%) & Inicial & Final & PU (\%) \\
\hline \multirow{2}{*}{$\mathrm{P} 1$} & 1 & 20,77 & 6,45 & 68,95 & 20,77 & 6,92 & 66,68 \\
\hline & 2 & 21,26 & 6,62 & 68,86 & 21,26 & 6,37 & 70,04 \\
\hline \multirow{2}{*}{$\mathrm{P} 2$} & 1 & 6,45 & 5,61 & 13,02 & 6,92 & 7,46 & - \\
\hline & 2 & 6,62 & 5,87 & 11,33 & 6,37 & 6,78 & - \\
\hline \multirow{2}{*}{ P3 } & 1 & 5,61 & 4,98 & 11,23 & 7,46 & 5,90 & 20,91 \\
\hline & 2 & 5,87 & 5,34 & 9,03 & 6,78 & 5,30 & 21,83 \\
\hline P4 & 2 & 5,34 & 5,26 & 1,50 & 5,30 & 5,61 & - \\
\hline
\end{tabular}

$\mathrm{P}$ - Período de secagem, em que $\mathrm{P}_{1}$ e $\mathrm{P}_{3}$ correspondem ao período diurno e $\mathrm{P}_{2}$ e $\mathrm{P}_{4}$ correspondem ao período noturno; $\mathrm{PU}$ - Perda de umidade.

Fonte: Elaboração dos autores.

No primeiro período de secagem (P1), correspondendo ao primeiro dia de secagem por exposição direta ao sol, os tratamentos foram submetidos às mesmas condições de secagem, o que justifica os teores de umidade finais e as porcentagens de perda de umidade semelhantes. No segundo período de secagem, correspondendo à primeira noite (P2), as amostras em secador acumulador de calor perderam mais de $10 \%$ de umidade, enquanto as amostras controle absorveram umidade. No terceiro período de secagem (P3), correspondendo ao segundo dia de secagem por exposição ao sol, as amostras do tratamento 1 atingiram a umidade final de 4,98\% b.s., com redução de mais de $11 \%$ 
no teor de umidade. A amostra controle perdeu mais umidade neste intervalo, o que é explicável pelo fato de haver absorvido umidade no período noturno. Comparando-se os teores de umidade final das amostras do tratamento 1 e sua amostra controle, verifica-se diferença de $0,92 \%$. Nas amostras do tratamento 2 , observa-se redução de umidade de cerca de $10 \%$, com a amostra controle apresentando perda de umidade de aproximadamente $22 \%$. No quarto período de secagem, correspondendo à secagem na segunda noite, as amostras do tratamento 2 (P4) repetiram o comportamento observado no intervalo P2, com a amostra no secador perdendo umidade e a amostra controle absorvendo umidade.

Ao final do processo de desidratação (Tabela 2 ), as amostras dos tratamentos 1 e 2 tiveram perda de umidade correspondendo a 76,02\% e 75,26\%, respectivamente, estando próximos aos resultados de Ronoh et al. (2009), que reportaram perda de umidade correspondendo a 76,70\% em sementes de amaranto, Midilli e Kucuk (2003), que encontraram perda de umidade de $73,79 \%$ em grãos de pistache com casca, Hii, Law e Cloke (2008), que relataram perda de umidade de 79,33\% em grãos de cacau e Doymaz (2011), que relataram perda de umidade de $83,24 \%$ em grãos de feijão.

Na Tabela 3 são apresentados os parâmetros de ajuste dos modelos Aproximação da Difusão, Dois Termos, Midilli, Page e Thompson aos dados experimentais da cinética de secagem das amostras dos tratamentos $1 \mathrm{e} 2$, com os respectivos coeficientes de determinação $\left(\mathrm{R}^{2}\right)$ e desvios quadráticos médios (DQM). Para as amostras controle (AC) referentes aos tratamentos 1 (AC1) e 2 (AC2) os ajustes foram feitos por trechos: $\mathrm{AC} 1$ [1] e $\mathrm{AC} 2$ [1] referentes ao primeiro período diurno de secagem e $\mathrm{ACl}$ [2] e AC2 [2] referentes ao segundo período diurno.

Para ambos os tratamentos, o modelo Dois Termos foi o que melhor se ajustou aos dados experimentais da secagem por exposição direta ao sol combinada com a secagem em secador acumulador de calor, com $\mathrm{R}^{2}$ superiores a 0,99 e os menores resultados de DQM. Para as amostras controle de ambos os tratamentos o modelo de Midilli foi o que melhor ajustou as cinéticas de secagem no primeiro e no segundo dia. Todos os modelos apresentaram valores de $\mathrm{R}^{2}$ superiores a 0,95 , podendo ser utilizados na predição da cinética de secagem dos grãos residuais de urucum com e sem óleo. Doymaz (2011), Khazaei (2008), Hii, Law e Cloke (2008), Al-Mahasneh et al. (2007) e Midilli e Kucuc (2003) estudaram secagem ao sol de quiabo, sementes de gergelim, grãos de cacau, cascas de sementes de gergelim e pistache com e sem casca, respectivamente, e obtiveram bons ajustes utilizando os modelos empregados neste trabalho. Clement et al. (2009) investigaram a secagem ao sol de sementes de cacau fermentadas e obtiveram ajustes com $\mathrm{R}^{2}$ superiores a 0,94 para os modelos Dois Termos, Page e Thompson. Akpinar (2008) ajustou os modelos Aproximação da Difusão, Dois Termos, Midilli, Page e Thompson aos dados experimentais da cinética de secagem de amora, e obtiveram ajustes com $\mathrm{R}^{2}$ superiores a 0,98 .

$\mathrm{Na}$ Tabela 4 são apresentados os valores dos coeficientes de difusividade dos grãos residuais de urucum submetidos à secagem por exposição direta ao sol combinada com secagem em secador acumulador de calor, e as amostras controle para as secagens no primeiro (1) e no segundo (2) período diurno. De acordo com Jittanit (2011), o coeficiente de difusividade indica a rapidez com que a umidade pode ser transferida a partir do interior para a superfície do produto. As difusividades determinadas nos grãos de urucum são da ordem de $10^{-9} \mathrm{~m}^{2} \mathrm{~s}^{-1}$, corroborando Madamba et al. (1996), que afirmam que em produtos agrícolas as difusividades apresentam magnitudes da ordem de $10^{-9}$ a $10^{-}$ ${ }^{11} \mathrm{~m}^{2} \mathrm{~s}^{-1}$. Produtos agrícolas diversos apresentam difusividades com magnitude de $10^{-9} \mathrm{~m}^{2} \mathrm{~s}^{-1}$, a exemplo de soja (NIAMNUY et al., 2012), cebolas (KALSE; PATIL; JAIN, 2012), resíduos de oliva (MILCZAREK et al., 2011), cenoura (BOTELHO et al., 2011), maçã (ZHU et al., 2010). Em relação aos tratamentos 1 e 2, nota-se que as amostras que não 
possuíam óleo (tratamento 2) apresentaram a maior difusividade no primeiro período de secagem, mas essa diferença desapareceu nas amostras controle no segundo período de secagem, sugerindo um comportamento padrão em que a influência do filme de óleo se faz sentir apenas no início da secagem.

Tabela 3. Parâmetros dos modelos, coeficientes de determinação $\left(\mathrm{R}^{2}\right)$ e desvios quadráticos médios (DQM) dos ajustes da cinética de secagem de grãos de urucum com e sem óleo.

\begin{tabular}{|c|c|c|c|c|c|c|c|c|}
\hline \multirow{2}{*}{ Modelo } & \multirow{2}{*}{ Amostra } & \multicolumn{7}{|c|}{ Parâmetros } \\
\hline & & $\mathrm{a}$ & $\mathrm{b}$ & $\mathrm{k}$ & $\mathrm{n}$ & $q$ & $\mathrm{R}^{2}$ & DQM \\
\hline \multirow{6}{*}{ 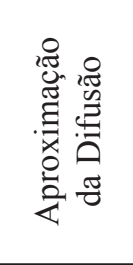 } & T1 & 0,8333 & 0,1020 & 0,0120 & - & - & 0,9985 & 0,0020 \\
\hline & $\mathrm{AC} 1$ (1) & 0,0290 & 0,0254 & 0,4480 & - & - & 0,9982 & 0,0018 \\
\hline & $\mathrm{AC} 1$ (2) & $-289,97$ & 0,9971 & 0,0123 & - & - & 0,9836 & 0,0370 \\
\hline & $\mathrm{T} 2$ & 0,8239 & 0,0857 & 0,0157 & - & - & 0,9973 & 0,0098 \\
\hline & $\mathrm{AC} 2(1)$ & 0,0331 & 0,0235 & 0,5145 & - & - & 0,9989 & 0,0085 \\
\hline & AC2 (2) & $-285,83$ & 0,9976 & 0,0114 & - & - & 0,9870 & 0,0351 \\
\hline \multirow{6}{*}{ 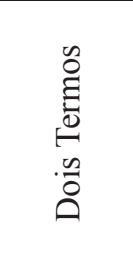 } & T1 & 0,8337 & 0,1679 & 0,0120 & - & 0,0012 & 0,9985 & 0,0015 \\
\hline & $\mathrm{AC} 1$ (1) & 0,8010 & 0,1907 & 0,0106 & - & 0,0178 & 0,9981 & 0,0031 \\
\hline & $\mathrm{AC} 1(2)$ & 0,5294 & 0,5294 & 0,0068 & - & 0,0068 & 0,9603 & 0,0356 \\
\hline & $\mathrm{T} 2$ & 0,8070 & 0,1657 & 0,0148 & - & 0,0013 & 0,9980 & 0,0027 \\
\hline & AC2 (1) & 0,4929 & 0,4923 & 0,0124 & - & 0,0124 & 0,9986 & 0,0056 \\
\hline & $\mathrm{AC} 2(2)$ & 0,6557 & 0,3774 & 0,0065 & - & 0,0065 & 0,9730 & 0,0393 \\
\hline \multirow{6}{*}{$\stackrel{\Xi}{\bar{Z}}$} & T1 & 1,0248 & 0,000031 & 0,0254 & 0,7773 & - & 0,9912 & 0,0298 \\
\hline & $\mathrm{AC} 1$ (1) & 0,9958 & $-0,000013$ & 0,0138 & 0,9613 & - & 0,9981 & 0,0004 \\
\hline & $\mathrm{AC} 1(2)$ & 0,9838 & $-0,000441$ & 0,0013 & 1,2481 & - & 0,9941 & 0,0021 \\
\hline & $\mathrm{T} 2$ & 1,0168 & 0,000017 & 0,0462 & 0,6810 & - & 0,9900 & 0,0196 \\
\hline & AC2 (1) & 0,9890 & $-0,000020$ & 0,0136 & 0,9785 & - & 0,9988 & 0,0009 \\
\hline & AC2 (2) & 0,9581 & $-0,000104$ & 0,0011 & 1,3135 & - & 0,9911 & 0,0012 \\
\hline \multirow{6}{*}{\begin{tabular}{l}
0 \\
\multirow{\infty}{\infty}{} \\
$\tilde{D}$
\end{tabular}} & $\mathrm{~T} 1$ & - & - & 0,0265 & 0,7575 & - & 0,9860 & 0,0537 \\
\hline & $\mathrm{AC} 1$ (1) & - & - & 0,0138 & 0,9644 & - & 0,9981 & 0,0048 \\
\hline & $\mathrm{AC} 1(2)$ & - & - & 0,0007 & 1,4317 & - & 0,9864 & 0,0358 \\
\hline & $\mathrm{T} 2$ & - & - & 0,0477 & 0,6673 & - & 0,9869 & 0,0585 \\
\hline & AC2 (1) & - & - & 0,0140 & 0,9756 & - & 0,9985 & 0,0109 \\
\hline & AC2 (2) & - & - & 0,0015 & 1,2876 & - & 0,9933 & 0,0366 \\
\hline \multirow{6}{*}{ 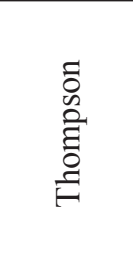 } & $\mathrm{T} 1$ & $-6,6629$ & 0,2934 & - & - & - & 0,9914 & 0,0337 \\
\hline & $\mathrm{AC} 1$ (1) & $-47,9134$ & 0,7632 & - & - & - & 0,9980 & 0,0069 \\
\hline & $\mathrm{AC} 1(2)$ & $-5722,69$ & 6,0095 & - & - & - & 0,9553 & 0,0086 \\
\hline & $\mathrm{T} 2$ & $-3,7962$ & 0,2815 & - & - & - & 0,9910 & 0,0416 \\
\hline & AC2 (1) & $-159,4350$ & 1,4200 & - & - & - & 0,9984 & 0,0104 \\
\hline & AC2 (2) & $-4653,94$ & 5,4181 & - & - & - & 0,9714 & 0,0230 \\
\hline
\end{tabular}

T1 e T2 - Secagem ao sol combinada com secagem em secador acumulador de calor dos tratamentos 1 e 2; AC1 - Amostras controle do tratamento 1; AC2 - Amostras controle do tratamento 2; (1) e (2) - Secagem da amostra controle no primeiro e segundo período diurno, respectivamente.

Fonte: Elaboração dos autores. 
Tabela 4. Valores médios dos coeficientes de difusividade dos grãos residuais de urucum

\begin{tabular}{ccc}
\hline Amostra & $\begin{array}{c}\text { Coeficiente de difusividade } \\
\left(\mathrm{m}^{2} \mathrm{~s}^{-1}\right)\end{array}$ & $\mathrm{R}^{2}$ \\
\hline Tratamento 1 & $1,55 \times 10^{-9}$ & 0,9524 \\
AC1 (1) & $2,38 \times 10^{-9}$ & 0,9376 \\
AC1 (2) & $1,27 \times 10^{-9}$ & 0,8130 \\
Tratamento 2 & $1,95 \times 10^{-9}$ & 0,9607 \\
AC2 (1) & $2,55 \times 10^{-9}$ & 0,9397 \\
AC2 (2) & $1,25 \times 10^{-9}$ & 0,8496 \\
\hline
\end{tabular}

AC1 - Amostras controle do tratamento 1; AC2 - Amostras controle do tratamento 2; (1) e (2) - Secagem da amostra controle no primeiro e segundo período diurno, respectivamente.

Fonte: Elaboração dos autores.

\section{Conclusão}

A utilização do secador acumulador de calor promoveu a secagem das amostras no período noturno, evitando absorção de umidade pelos grãos residuais de urucum com e sem óleo, com consequente redução de riscos de deterioração desencadeada neste período.

O secador acumulador de calor foi eficaz como complemento à secagem por exposição ao sol, mantendo uma temperatura adequada à secagem no período noturno.

Os modelos Aproximação da Difusão, Dois Termos, Midilli, Page e Thompson resultaram em bons ajustes à cinética de secagem dos grãos residuais de urucum com e sem óleo, com destaque para os modelos Dois Termos e Midilli.

Os grãos de urucum sem óleo (tratamento 2) apresentaram maior taxa de secagem apenas no início do processo, não se justificando a remoção do óleo considerando-se apenas esse critério.

\section{Agradecimentos}

Ao CNPq e à CAPES pelo apoio financeiro e à indústria alimentícia Maratá pela doação dos grãos residuais de urucum.

\section{Referências}

AKPINAR, E. K. Mathematical modelling and experimental investigation on sun and solar drying of white mulberry. Journal of Mechanical Science and Technology, Heidelberg, v. 22, n. 8, p. 1544-1553, 2008.

AL-MAHASNEH, M. A.; RABABAH, T. M.; ALSHBOOL, M. A.; YANG, W. Thin-layer drying kinetics of sesame hulls under forced convection and open sun drying. Journal of Food Process Engineering, Trumbull, v. 30, n. 3, p. 324-337, 2007.

ASSOCIATION OF OFFICIAL ANALYTICAL CHEMISTS - AOAC. Official Methods of Analysis. $18^{\text {th }}$ ed. Washington: USA, 2010. 1094 p.

BELESSIOTIS, V.; DELYANNIS, E. Solar drying. Solar Energy, Freiburg, v. 85, n. 8, p. 1665-1691, 2011.

BOTELHO, F. M.; CORRÊA, P. C.; GONELI, A. L. D.; MARTINS, M. A.; MAGALHÃES, F. E. A.; CAMPOS, S. C. Periods of constant and falling-rate for infrared drying of carrot slices. Revista Brasileira de Engenharia Agrícola e Ambiental, Campina Grande, v. 15, n. 8, p. 845-852, 2011.

CARDARELLI, C. R.; BENASSI, M. T.; MERCADANTE, A. Z. Characterization of different annatto extracts based on antioxidant and colour properties. LWT - Food Science and Technology, Zurich, v.41, n. 9, p. 1689-1693, 2008.

CARDEÑOSA, V.; LUNAR, M. L.; RUBIO, S. Generalized and rapid supramolecular solvent-based sample treatment for the determination of annatto in food. Journal of Chromatography A, Amsterdan, v. 1218, n. 50, p. 8996-9002, 2011.

CARVALHO, P. R.; CIPOLLI, K. M. V. A. B.; ORMENESE, R. C. S. C.; CARVALHO, P. R. N.; SILVA, M. G. Supplementation carotenoid compounds derived from seed integral ground annatto (Bixa orellana L.) in 
the feed laying hens to produce eggs special. Pakistan Journal of Nutrition, Faisalabad, v. 8, n. 12, p. 19061909, 2009.

CLEMENT, A. D.; EMMANUEL, A. N.; KOUAMÉ, P.; BENJAMIN, Y. K. Mathematical modelling of sun drying kinetics of thin layer cocoa (Theobroma cacao) beans. Journal of Applied Sciences Research, Washington, v. 5, n. 9, p. 1110-1116, 2009.

CORLETT, F. M. F.; BARROS, A .C. S. A.; VILLELA, F. A. Qualidade fisiológica de sementes de urucum armazenadas em diferentes ambientes e embalagens. Revista Brasileira de Sementes, Londrina, v. 29, n. 2, p. 148-158, 2007.

CRANK, J. The mathematics of diffusion. London: Oxford University Press, 1975. 414 p.

DIÓGENES, A. M. G. Secagem solar e convencional de grãos de abóbora. 2010. Dissertação (Mestrado em Engenharia Agrícola) - Universidade Federal de Campina Grande, Campina Grande.

DOYMAZ, I. Drying of green bean and okra under solar energy. Chemical Industry \& Chemical Engineering Quarterly, Beograd, v. 17, n. 2, p. 199-205, 2011.

. Drying of pomegranate seeds using infrared radiation. Food Science and Biotechnology, Vietnam, v. 21, n. 5, p. 1269-1275, 2012.

DOYMAZ, I.; ISMAIL, O. Drying characteristics of sweet cherry. Food and Bioproducts Processing, London, v. 89, n. 1, p. 31-38, 2011.

FAGUNWA, A. O.; KOYA, O. A.; FABORODE, M. O. Development of an intermittent solar dryer for cocoa beans. Agricultural Engineering International: the CIGR Journal, Beijing, v. 11, n. 1, p. 1-14, 2009.

GARAU, M. C.; SIMAL, S.; FEMENIA,A.; ROSSELLÓ, C. Drying of orange skin: drying kinetics modeling and functional properties. Journal of Food Engineering, Oxford, v. 75, n. 2, p. 288-295, 2006.

GARAU, M. C.; SIMAL, S.; ROSSELLÓ, C.; FEMENIA, A. Effect of air-drying temperature on physico-chemical properties of dietary fibre and antioxidant capacity of orange (Citrus aurantium v. Canoneta) by-products. Food Chemistry, Washington, v. 104, n. 3, p. 1014-1024, 2007.

HARDER, M. N. C.; CANNIATTI-BRAZACA, S. G.; COELHO, A. A. D.; SAVINO, V. J. M.; FRANCO, C. F. O. Cholesterol and iron availability in yolk of laying hens feed with annatto (Bixa orellana). Animal, London, v. 1, n. 3, p. 477-482, 2007.

HII, C. L.; LAW, C. L.; CLOKE, M. Modelling of thin layer drying kinetics of cocoa beans during artificial and natural drying. Journal of Engineering Science and Technology, Kuala Lumpur, v. 3, n. 1, p. 1-10, 2008.

JENA, J.; DAS, H. Modelling for vacuum drying characteristics of coconut presscake. Journal of Food Engineering, Oxford, v. 79, n. 1, p. 92-99, 2007.

JITTANIT, W. Kinetics and temperature dependent moisture diffusivities of pumpkin seeds during drying. Kasetsart Journal: Natural Science, Bangkok, v. 45, n. 1, p. 147-158, 2011.

KALSE, S. B.; PATIL, M. M.; JAIN, S. K. Microwave drying of onion slices. Research Journal of Chemical Sciences, Dodoma, v. 2, n. 4, p. 57-60, 2012.

KHAZAEI, J. Natural drying characteristics of sesame seeds. Cercetări Agronomice în Moldova, Chişinău, v. 41, n. 3, p. 5-22, 2008.

KONG, K. W.; ISMAIL, A.; TAN, C. P.; RAJAB, N. F. Optimization of oven drying conditions for lycopene content and lipophilic antioxidant capacity in a by-product of the pink guava puree industry using response surface methodology. LWT - Food Science and Technology, Zurich, v. 43, n. 5, p. 729-735, 2010.

KUMAR, N.; SARKAR, B. C.; SHARMA, H. K. Mathematical modelling of thin layer hot air drying of carrot pomace. Journal of Food Science and Technology, Oxford, v. 49, n. 1, p. 33-41, 2012.

MADAMBA, P. S.; DRISCOLL, R. H.; BUCKLE, K. A. The thin-layer drying characteristics of garlic slices. Journal of Food Engineering, Oxford, v. 29, n. 1, p. 7597, 1996.

MIDILLI, A.; KUCUK, H. Mathematical modeling of thin layer drying of pistachio by using solar energy. Energy Conversion and Management, Oxford, v. 44, n. 7, p. 1111-1122, 2003.

MIDILLI, A.; KUCUK, H.; YAPAR, Z. A new model for single layer drying. Drying Technology, New York, v. 20, n. 7, p. 1503-1513, 2002.

MILCZAREK, R. R.; DAI, A. A.; OTONI, C. G.; McHUGH, T. H. Effect of shrinkage on isothermal drying behavior of 2-phase olive mill waste. Journal of Food Engineering, Oxford, v. 103, n. 4, p. 434-441, 2011.

MOHSENIN, N. N. Physical properties of plant and animal materials. New York: Gordon and Breach Publishers. 1986. $841 \mathrm{p}$.

MONTERO, I.; BLANCO, J.; MIRANDA, T.; ROJAS, S.; CELMA, A. R. Design, construction and performance testing of a solar dryer for agroindustrial by-products. Energy Conversion and Management, Oxford, v. 51, n. 7, p. 510-1521, 2010. 
NIAMNUY, C.; NACHAISIN, M.; POOMSA-AD, N.; DEVAHASTIN, S. Kinetic modelling of drying and conversion/degradation of isoflavones during infrared drying of soybean. Food Chemistry, Washington, v. 133, n. 3, p. 946-952, 2012.

NUTHONG, P.; ACHARIYAVIRIYA, A.; NAMSANGUAN, K.; ACHARIYAVIRIYA, S. Kinetics and modeling of whole longan with combined infrared and hot air. Journal of Food Engineering, Oxford, v. 102, n. 3, p. 233-239, 2011.

OFOSU, I. W.; APPIAH-NKANSAH, E.; OWUSU, L.; APEA-BAH, F. B.; ODURO, I.; ELLIS, W. O. Formulation of annatto feed concentrate for layers and the evaluation of egg yolk color preference of consumers. Journal of Food Biochemistry, Davis, v. 34, n. 1, p. 6677, 2010.

PARIZE, A. L.; SOUZA, T. C. R.; BRIGHENTE, I. M. C. Obtenção e caracterização de microesferas de quitosana contendo o corante urucum. Tecnologia \& Ciência Agropecuária, João Pessoa, v. 2, n. 1, p. 15-18, 2008.

PRASAD, J.; VIJAY, V. K. Open sun drying of Tinospora cordifolia, Curcuma longa L. and Zingiber officinale. Thermal analysis. Food Science and Technology International, London, v. 11, n. 6, p. 409-416, 2005.

QUEIROZ, A. J. M.; DANTAS, H. J.; FIGUEIREDO, R. M. F.; MELO, K. S. Solar drying of jack fruit almonds. Engenharia Agrícola, Jaboticabal, v. 31, n. 6, p. 11501161, 2011.

RÊGO, A. C.; CÂNDIDO, M. J. D.; PEREIRA, E. S.; FEITOSA, J. V.; RÊGO, M. M. T. Degradação de silagens de capim-elefante contendo subproduto do urucum. Revista Ciência Agronômica, Fortaleza, v. 41, n. 3, p. 482-489, 2010.

ROBERTS, J. S.; KIDD, D. R.; PADILLA-ZAKOUR, O. Drying kinetics of grape seeds. Journal of Food Engineering, Oxford, v. 89, n. 4, p. 460-465, 2008.

RONOH, E. K.; KANALI, C. L.; MAILUTHA, J. T.; SHITANDA, D. Modeling thin layer drying of amaranth seeds under open sun and natural convection solar tent dryer. Agricultural Engineering International: the CIGR E-journal, Beijing, v. 11, n. 1, p. 1-13, 2009.

SACILIK, K. The thin-layer modelling of tomato drying process. Agriculturae Conspectus Scientificus, Zagreb, v. 72, n. 4, p. 343-349, 2007.

SANTOS, D. C.; QUEIROZ, A. J. M.; FIGUEIRÊDO, R. M. F.; OLIVEIRA, E. N. A. Drying of waste grains flour of annatto by using solar energy. African Journal of Agricultural Research, Lagos, v. 7, n. 47, p. 6281-6288, 2012.
SANTOS, D. C.; QUEIROZ, A. J. M.; FIGUEIRÊDO, R. M. F.; OLIVEIRA, E. N. A. Cinética de secagem de farinha de grãos residuais de urucum. Revista Brasileira de Engenharia Agrícola e Ambiental, Campina Grande, v. 17, n. 2, p. 223-231, 2013.

SILVA, J. H. V.; SILVA, E. L.; JORDÃO FILHO, J.; RIBEIRO, M. L. G. Efeitos da inclusão do resíduo da semente de urucum (Bixa Orellana L.) na dieta para frangos de corte: desempenho e características de carcaça. Revista Brasileira de Zootecnia, Viçosa, v. 34, n. 5, p. 1606-1613, 2005.

SILVA, M. G.; CARVALHO, P. R.; TAVARES, P. E. R.; CARVAlHO, P. R. N.; CIPOLLI, K. M. V. A. B.; ORMENESE, R. C. S. C. Potential of annatto in agroindustries and animal feed: fragrance, flavor, taste and color of Bixa orellana L. derivatives. Journal of Applied Sciences Research, Washington, v. 5, n. 12, p. 2482-2488, 2009.

TANG, Z.; CENKOWSKI, S.; IZYDORCZYK, M. Thin-layer drying of spent grains in superheated steam. Journal of Food Engineering, Oxford, v. 67, n. 4, p. 457$465,2005$.

TONANI，F. L.; RUGGIERI，A. C.; GUIM，A.; ANDRADE, P.; QUEIROZ, A. C.; SANTOS, H. Q.; MALHEIROS, E. B. Avaliação nutricional do resíduo de urucum (Bixa orellana, L.), após a extração do corante. Ars Veterinaria, Jaboticabal, v. 16, n. 2, p. 118-121, 2000.

VEGA-GALVEZ, A.; MIRANDA, M.; DIAZ, L. P.; LOPEZ, L.; RODRIGUEZ, K.; SCALA, K. Effective moisture diffusivity determination and mathematical modeling of the drying curves of the olive-waste cake. Bioresource Technology, Oxford, v. 101, n. 19, p. 7265 7270, 2010.

VIJAYARAJ, B.; SARAVANAN, R.; RENGANARAYANAN, S. Studies on thin layer drying of bagasse. International Journal of Energy Research, Oxford, v. 31, n. 4, p. 422-437, 2007.

WANG, Z.; SUN, J.; LIAO, X.; CHEN, F.; ZHAO, G.; WU, J.; HU, X. Mathematical modeling on hot air drying of thin layer apple pomace. Food Research International, Kidlington, v. 40, n. 1, p. 39-46, 2007.

ZHU, Y.; PAN, Z.; McHUGH, T. H.; BARRETT, D. M. Processing and quality characteristics of apple slices processed under simultaneous infrared dry-blanching and dehydration with intermittent heating. Journal of Food Engineering, Oxford, v. 97, n. 1, p. 8-16, 2010. 